\title{
Expanding options to manage traumatic thoracic vascular injuries
}

\author{
S. Ram Kumar, MD, PhD, FACS
}

\author{
From the Division of Cardiac Surgery, Department of Surgery, University of Southern California; and the Heart \\ Institute, Children's Hospital of Los Angeles, Los Angeles, Calif. \\ Disclosures: Author has nothing to disclose with regard to commercial support. \\ Received for publication Oct 4, 2017; accepted for publication Oct 7, 2017; available ahead of print Nov 15, 2017. \\ Address for reprints: S. Ram Kumar, MD, PhD, FACS, Assistant Professor of Surgery and Pediatrics, Children's \\ Hospital, Los Angeles, 4650 Sunset Blvd, Mailstop 66, Los Angeles, CA 90027 (E-mail: rsubramanyan@chla. \\ usc.edu). \\ J Thorac Cardiovasc Surg 2018;155:e77-8 \\ $0022-5223 / \$ 36.00$ \\ Copyright (c) 2017 by The American Association for Thoracic Surgery \\ https://doi.org/10.1016/j.jtcvs.2017.10.007
}

Pulmonary artery injuries are rare. The vast majority result from iatrogenic causes, most frequently from injury during placement of monitoring catheters in the pulmonary artery or percutaneous interventions in the right ventricular outflow tract (Figure 1). Pseudoaneurysms of the pulmonary artery can result from old suture lines ${ }^{1}$ or from dilation of prosthetic materials used for surgical reconstruction. Very rarely, mycotic pseudoaneurysms and chronic infection-related pulmonary artery tears have been observed.

Traumatic injury to the mediastinal pulmonary artery can result from both blunt and penetrating trauma. As in most cases of penetrating trauma to mediastinal structures, penetrating pulmonary artery injuries can be lethal, and the outcome is heavily reliant on time to intervention. There have been a few case reports of blunt trauma causing

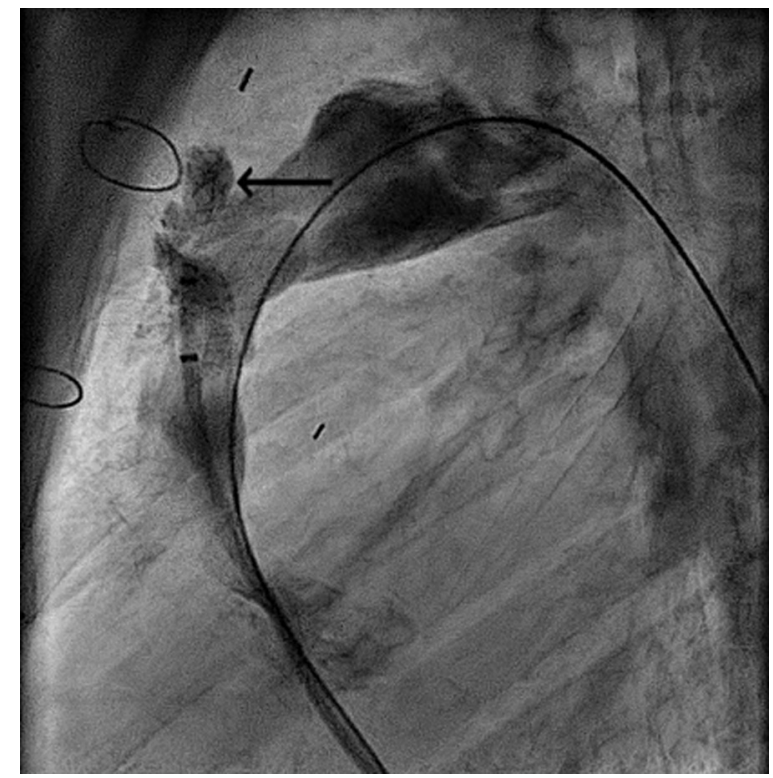

FIGURE 1. Angiogram showing injury to pulmonary homograft with contrast extravasation (arrow) during attempted balloon dilation.

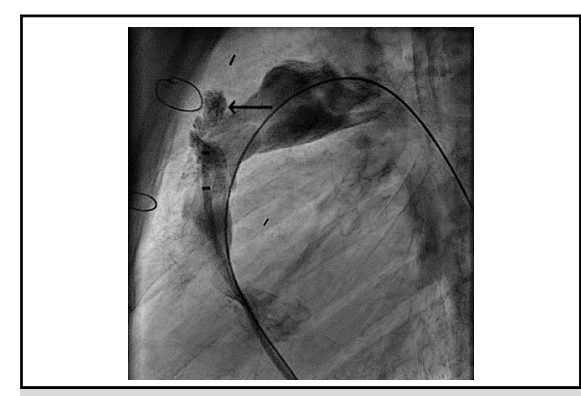

Angiogram showing injury to pulmonary homograft (arrow) during attempted balloon dilation.

\section{Central Message}

The endovascular approach expands available therapeutic options in the management of traumatic pulmonary artery injuries.

See Article page e73.

pulmonary artery injury. These cases are generally associated with multiple other injuries, which can complicate their management. Presentation can range from a contained hematoma and pseudoaneurysm to a large hemopericardium and tamponade. In general, among patients who have survived transport to the hospital, pulmonary artery injuries have been successfully repaired surgically. In this issue of the Journal, Palmieri and colleagues ${ }^{2}$ report percutaneous management of a traumatic pulmonary artery pseudoaneurysm in an 8-year-old child. With the rapid development of novel and versatile sheaths and devices and the increase in interventional expertise, it is natural that the indications for endovascular management continue to expand. Especially in the field of trauma, this should come as no surprise. The management of blunt thoracic aortic injury has undergone rapid change during the last decade, such that today endovascular repair not only is safe and reliable, but also independently protects against aortic injury-related mortality.

The advantages of an endovascular approach to serious thoracic vascular injuries are intuitively obvious. Although feasible, surgical management comes with significant morbidity and can detract from attention to the other serious injuries that frequently coexist. Although infrequent, the potential need for cardiopulmonary bypass and the required anticoagulation can be a major concern in patients with significant associated injuries. Given what we know about the options to manage pulmonary artery injuries then, can 
one come up with definitive guidelines to direct appropriate care? First, in large part because of the rarity of these injuries, appropriate data-driven management algorithms are difficult to establish. There is little known about the natural history of contained hematomas and pseudoaneurysms such as the one seen in the patient in the report of Palmieri and colleagues. ${ }^{2}$ It is not clear which of these can be safely observed through time. Second, despite technical advances with percutaneous management, appropriate devices are still restricted to offlabel emergency use, especially in children. The logistical challenge of having the expertise required for these complex interventions available around the clock cannot be overlooked. Finally, the durability and long-term outcomes of the implanted devices are unknown. It is our responsibility to diligently follow and accrue data related to the performance of these percutaneous devices over time.
Expansion of the options available to approach traumatic thoracic vascular injuries is a welcome relief to both patients and physicians. The question of how best to determine the timing and modality of intervention still needs to be addressed by rigorous, multi-institutional, prospective data.

\section{References}

1. Shashidharan S, Wells WJ, Detterich J, Wong J, Kumar SR. Giant pseudoaneurysm of reconstructed right ventricular outflow tract. Ann Thorac Surg. 2015; 100:734.

2. Palmieri VJ, Heal ME, Chowdhury SM, Bandisode VM. Balloon-expandable covered stent implantation for treatment of a traumatic pulmonary artery pseudoaneurysm in a pediatric patient. J Thorac Cardiovasc Surg. 2018;155:e73-6.

3. DuBose JJ, Leake SS, Brenner M, Pasley J, O'Callaghan T, Luo-Owen X, et al; Aortic Trauma Foundation. Contemporary management and outcomes of blunt thoracic aortic injury: a multicenter retrospective study. J Trauma Acute Care Surg. 2015;78:360-9. 